\title{
KUNST TONEN AAN HET QING-HOF: DE QIANLONG-KEIZER GETOOND
}

Alvorens het paleismuseum in Beijing een museum werd, was het een keizerlijk paleis en verblijfplaats van de heersers van de Ming- en de Qingdynastie. Het vormde het rituele hart van het Chinese keizerrijk. Hier, èn in het Nationale Paleismuseum in Taipei, bestaat het overgrote deel van de collectie uit de verzameling van keizer Qianlong (r. 1736-1795), de grootste verzameling Chinese kunstvoorwerpen die ooit bijeen werd gebracht. De wijze waarop Qianlong voorwerpen aanmerkte als kunst(voorwerpen) en de wijze waarop deze werden tentoongesteld hebben in veel opzichten bepaald hoe moderne musea Chinese kunst presenteren. Westerse musea trachten veelvuldig een beeld van 'China' op te roepen in hun opstellingen en tegenwoordig kunnen geleerden en conservatoren er niet onderuit om direct de confrontatie aan te gaan met de keizerlijke kunstexpertise van de Qing. Zij kunnen de criteria die Qianlong hanteerde bij het verzamelen, beoordelen en tentoonstellen van kunstschatten accepteren, aanpassen of resoluut afwijzen. De keizerlijke gebouwen van de Qing-dynastie waren rijk gevuld met wat musea tegenwoordig als 'kunstvoorwerpen' aanmerken. Deze kunstvoorwerpen werden - naast objecten die door de keizers zeker niet als 'kunst' werden bestempeld - op manieren gebruikt die ze een betekenis gaven die dikwijls totaal verschilde van de betekenissen die hedendaagse musea impliceren door hun wijze van tentoonstelling. In dit artikel wordt een aantal aspecten van het tentoonstellen van de keizerlijke Qing belicht, die ons helpen om de wezenlijke verschillen tussen de moderne praktijk en die van de vroegere keizers te onderscheiden.

Gelijk voorgaande dynastieën was ook het Qing-hof gevuld met kunstschatten. Zo lijkt het althans op de schilderijen. Schilderijen vormen een van de meest cruciale informatiebronnen over het tentoonstellen van kunstvoorwerpen. Op een vroeg $18^{c}$-eeuws schilderij ( $\mathrm{afb}$. 1) zien we een vrouw die is gezeten aan een rijk gedecoreerde tafel. De schildering is een van de 12 rollen die oorspronkelijk waren gemonteerd als een twaalfdelig scherm, dat was vervaardigd voor Prins Yinzhen, de latere keizer Yongzheng (r. 17231735). Op de tafel staan een antiek brons, een inktsteen, en een flesje van keramiek. In de rijk gedecoreerde nissen staan meer bronzen, stukken porselein en andere keramiek, alsook een klein $18^{\mathrm{c}}$-eeuws wit stuk jade dat een kopie is van een oud bronzen vat, verder een stapel boeken in zijden cassettes, een gesneden jaden tafelscherm en zelfs een exotische Japanse lakdoos. De uitstalling van deze kunstvoorwerpen lijkt te zijn afgestemd op hun visuele attractiviteit en lijkt geen afspiegeling te vormen van enige andere 

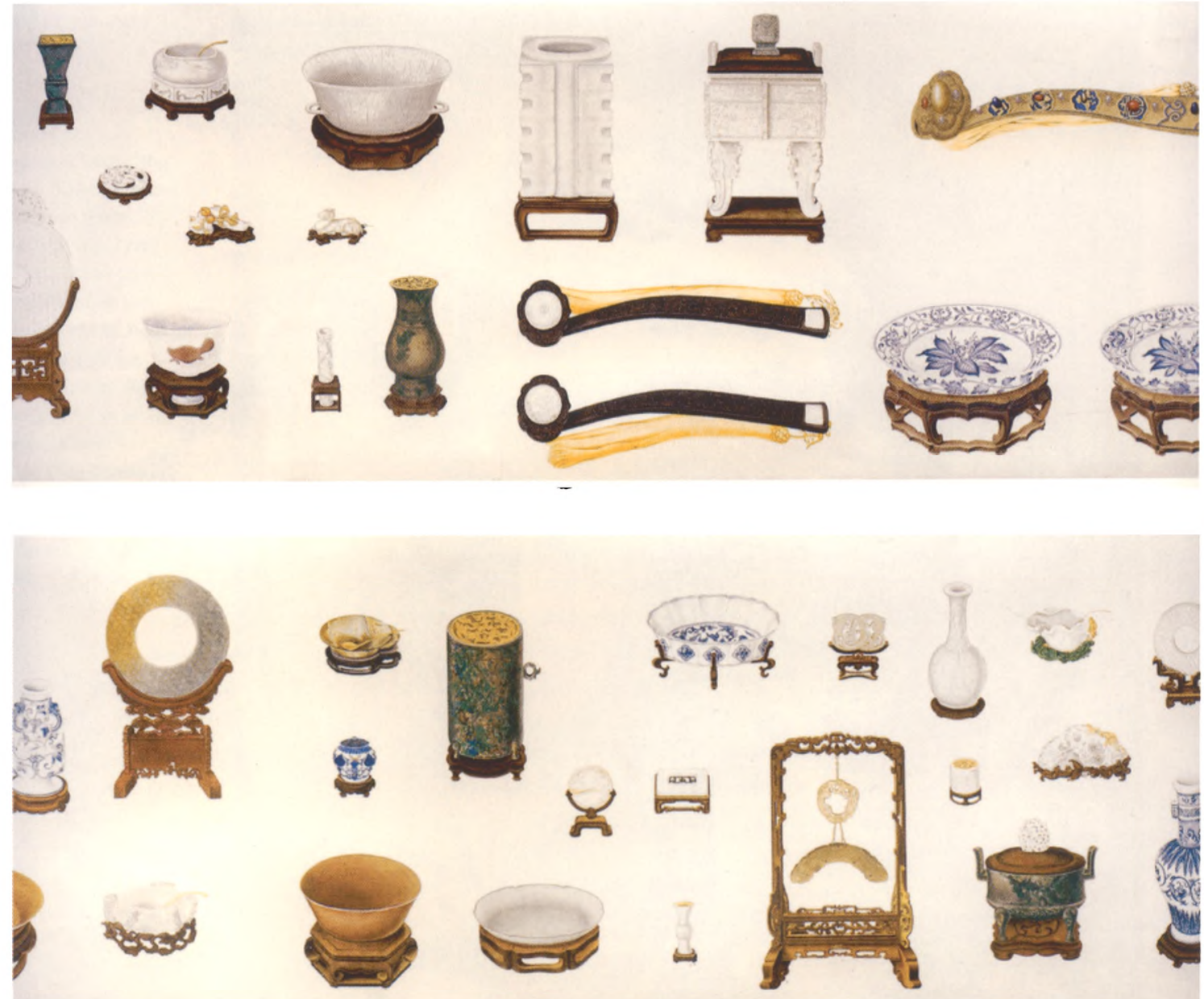

Afbeelding 2

Anonieme hofkunstenaars, Guwan tu, begin $18^{e}$ eeuw, handrol, inkt en kleur op papier (detail), 62,5 × $1502 \mathrm{~cm}$ Uit: Rawski en Rawson (zie noot 7), cat. 168 organisatorische systematiek. Talloze andere schilderijen van hofinterieurs vertonen een overeenkomstige opstelling van waardevolle objecten. Een deel van een hoogst ongebruikelijke rolschildering die voor keizer Yongzheng werd geschilderd (afb. 2) toont veel dezelfde soort objecten als in het schilderij van de hofvrouw. De rol bevat uiterst zorgvuldig geschilderde afbeeldingen van individuele kunstvoorwerpen en men denkt dat deze en de enige andere overgebleven bijbehorende rol (behorend tot een grotere groep van een onbekend aantal) een visuele inventaris van de keizerlijke collecties vormen. ${ }^{1}$ De objecten zijn bijna alle voorzien van een voetstuk. Jade schijven en ander jade snijwerk hebben houders om hen overeind te houden en vaten met een wijde opening zijn vaak voorzien van een deksel. In de vele schilderijen van hofinterieurs van de Qing staan objecten bijna altijd op deze manier afgebeeld - opgesteld op een voet of een steun. De rolschilderingen van keizer Yongzheng zijn beschreven met de titel Guwan tu, hetgeen kan worden vertaald als 'schilderijen van antiquiteiten voor genoegen'. Over het algemeen werden de anonieme illustraties zorgvuldig vervaardigd met gebruikmaking van Europese modelleringtechnieken in donker en licht, alsof het 'portretten' van individuele kunstwerken betrof. Een aantal objecten op de Guwan turollen kan daadwerkelijk in de vroegere keizerlijke collecties worden thuisgebracht. Een daarvan is een blauw-wit porseleinen pot met deksel ( $(a b$ r 3 ) access 


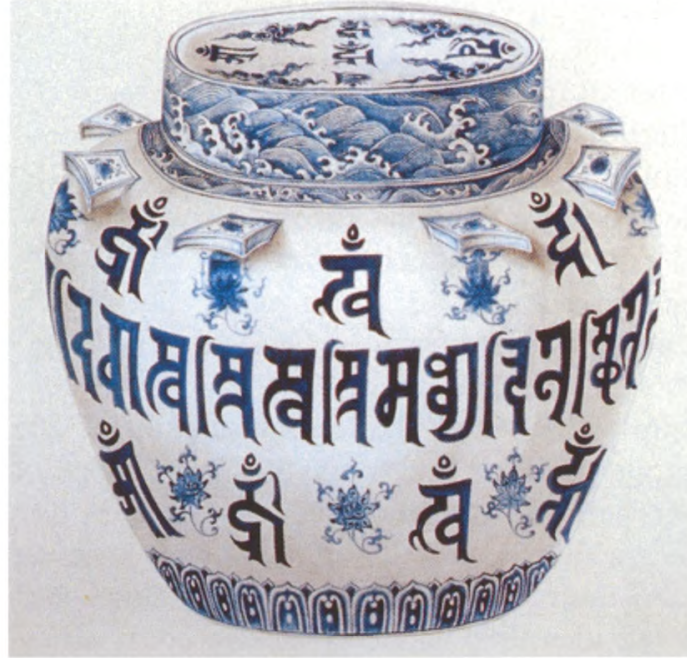

\section{Afbeelding 3 \\ Guwan tu, detail met voorstelling van Ming. porselein met Tibetaanse inscripties. Uit: Shane McCausland (zie noot 1), fig. 7}

\begin{abstract}
Afbeelding 4
Bel met de inscriptie Zi su, Lenteen Herfstperiode, laat $6^{\mathrm{e}}$ - vroeg $5^{e}$ eeuw v.Chr., brons, hardhouten standaard, hoogte bel $22,2 \mathrm{~cm}$, breedte $12,2 \mathrm{~cm}$ Uit: Fong en Watt (zie noot), pl. 38
\end{abstract}

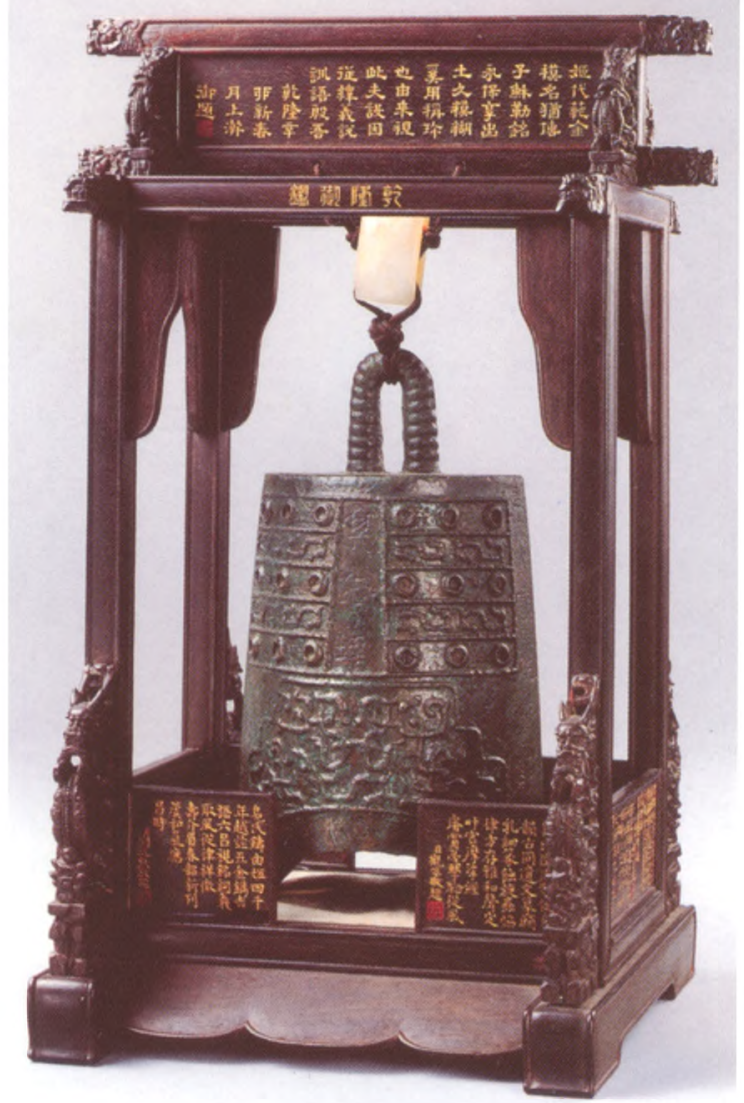

uit de Xuande-periode (1426-1435). Dit vroeg $15^{\mathrm{c}}$-eeuwse stuk porselein is een opvallend object: bedekt met inscripties in het Tibetaans en andere tekens getuigt het van de interesse van de Ming-keizers in het Tibetaans boeddhisme. We zullen later terugkomen op dit vat - en op het Tibetaans boeddhisme.

De opstelling van kunstwerken gaf vaak aanleiding tot vertoon van keizerlijke kennis en kunstkennerschap. Een oude bronzen bel uit de keizerlijke collectie ( $\mathrm{afb} .4$ ) is geplaatst in een opvallend bewerkte houder die speciaal voor dit doel is vervaardigd, met veel ruimte voor inscripties. De belangrijkste inscriptie is de tekst van keizer Qianlong, die is gegraveerd op het bovenstuk van de houder (de foto toont de achterkant met het eind van de inscriptie waarin een datum staat die overeenkomt met het jaar 1771). De inscripties op de panelen eronder zijn van de hand van leden van het keizerlijke hof. In de dwarslat boven de bel staat het opschrift van vier karakters gekerfd Qianlong yujian, 'gewaardeerd door keizer Qianlong'. Een dergelijke inscriptie, die overeenkomt met opschriften die werden gebruikt op een aantal keizerlijke stempels, geeft aan dat de keizer de Chinese traditie volgde van kennerschap van antiquiteiten. Op schilderijen en kalligrafieën zou de keizerlijke tekst

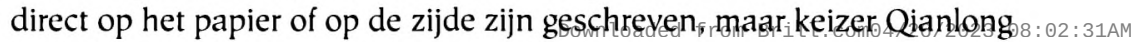
plaatste ook talloze inscripties direct op de objecten zelf, alsook op die free access 


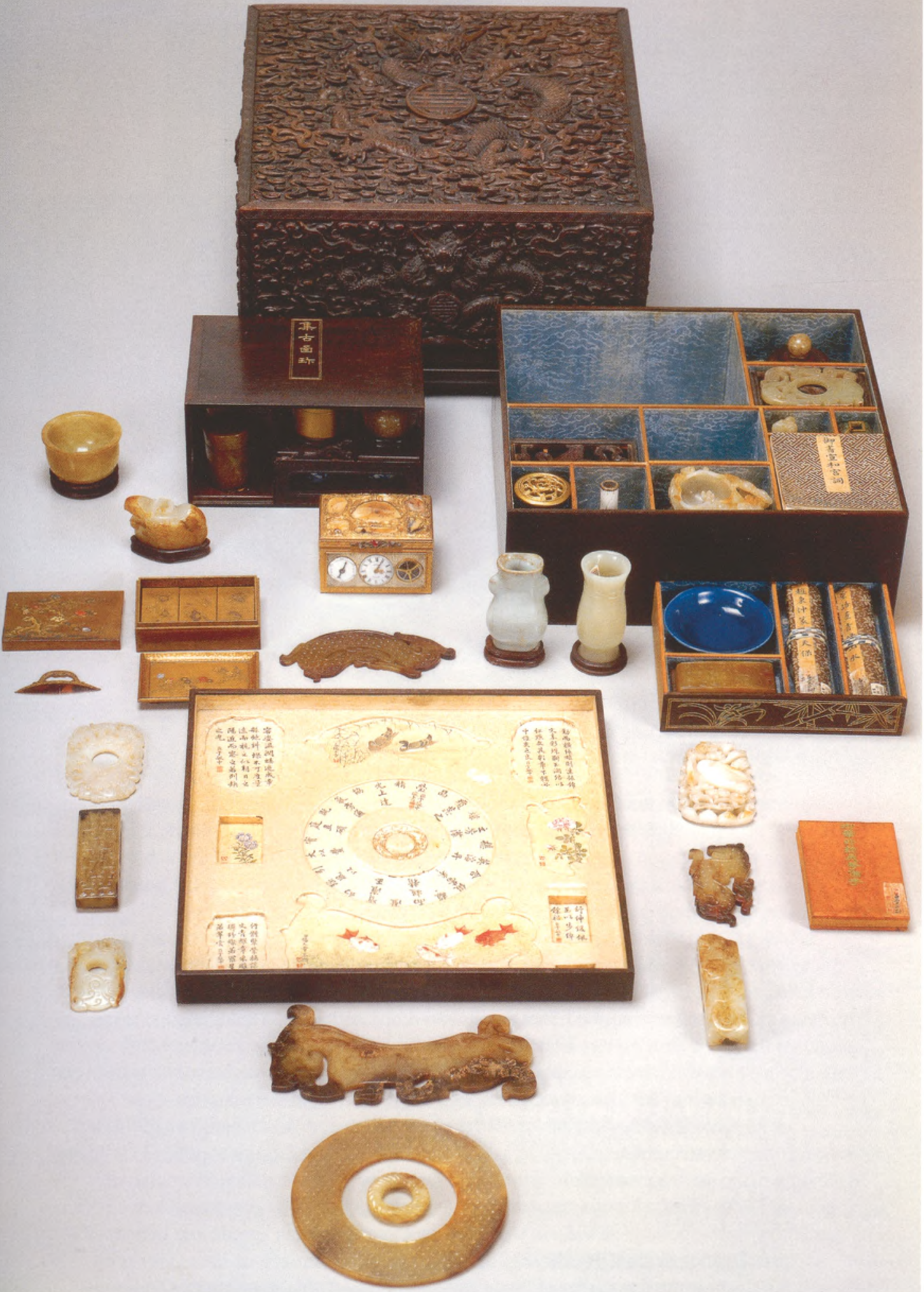




\section{Afbeelding 5}

Schatkist met 47 objecten, midden $18^{\circ}$ eeuw, rood sandelhout, $30,5 \times$ $30,3 \times 16,5 \mathrm{~cm}$ Uit: Feng Mingzhu e.a. (red.), Emperor Ch'ienlung's Grand Cultural Enterprise, Taipei, 2002, cat. 1-41, pp. 52-53

voetstukken en steunen, de deksels en dozen voor de objecten. Wie een dergelijk kunstwerk bekeek, zag meteen ook de keizerlijke inscripties. Soms lijkt er naar de modern Westerse opvatting geen helder onderscheid te bestaan tussen opslag en tentoonstelling in het $18^{\mathrm{e}}$-eeuwse keizerlijke Qinghof. Een van de vernieuwingen van die periode is het samenvoegen van objecten in 'schatkisten'. ${ }^{2}$ Zulke kabinetjes zijn in feite Qianlongs equivalent van een rariteitenkabinet: een gemengde verzameling van natuurlijke en door de mens vervaardigde objecten, die in Europa de voorloper van moderne museumcollecties was. Een schatkist van sandelhout (afb. 5) bevat ongeveer 47 objecten, waaronder archaïsche en contemporaine $18^{c}$-eeuwse jades, miniaturen in keramiek in de stijl van de Song-dynastie, handrollen en boeken, een kleine doos in Europese stijl met een uurwerk en twee andere wijzerplaten, en voorbeelden van Japans lakwerk. De vele miniatuurkabinetten van keizer Qianlong bevatten een microkosmos van kunstkennerschap en het verzamelen in de $18^{\mathrm{c}}$ eeuw. Op kleine handrollen staan geschreven teksten als titels, gedichten en andersoortige beschrijvingen tezamen met illustraties (soms afbeeldingen van specifieke objecten, soms decoratieve schilderijen) op de plekken waar eigenlijk individuele objecten horen. Grotere dozen bevatten kleine dozen met daarin objecten en hun standaards. De hele verzameling is op haar beurt geplaatst in een zeer rijk gedecoreerde doos of kabinet. Het bekijken van de objecten in een 'schatkist' bracht een gevoel met zich mee van intiem contact met de kunstwerken: het aanraken van de objecten, het lezen van de titels en de inscripties, en het terugplaatsen van de objecten op de daartoe bestemde plaats. Tentoonstellen is hier een intieme persoonlijke aangelegenheid.

In zeker één geval diende een compleet keizerlijk gebouw ter opslag en vertoon van kunstwerken. Het gebouw droeg de naam Yuanyingguan, 'uitzicht op immense oceanen' (afb. 6), en werd aanvankelijk gebouwd om een set van Beauvais tapisserieën in onder te brengen die door Lodewijk XV van Frankrijk naar keizer Qianlong waren gestuurd. Yuanyingguan bevatte ook talloze andere Europese objecten die deel uitmaakten van Qianlongs collectie. Vermoedelijk beschouwde de keizer deze objecten als tribuutgeschenken van verre landen. In verslagen staat opgetekend dat ze werden opgeslagen in een kamer van ruim 20 meter lang, die gevuld was met

\footnotetext{
Afbeelding 6 Toegeschreven aan Yilantai (18e eeuw), Hoofdfaçade van het Yuanying Guan, kopergravure, 1783-1786, $50 \times$ $87 \mathrm{~cm}$, nummer 14 van 20 afbeeldingen van de Europese Paleizen van het Yuanmingyuan Uit: Qingdai gongting huihua (zie afb.1), cat. 134.14
}

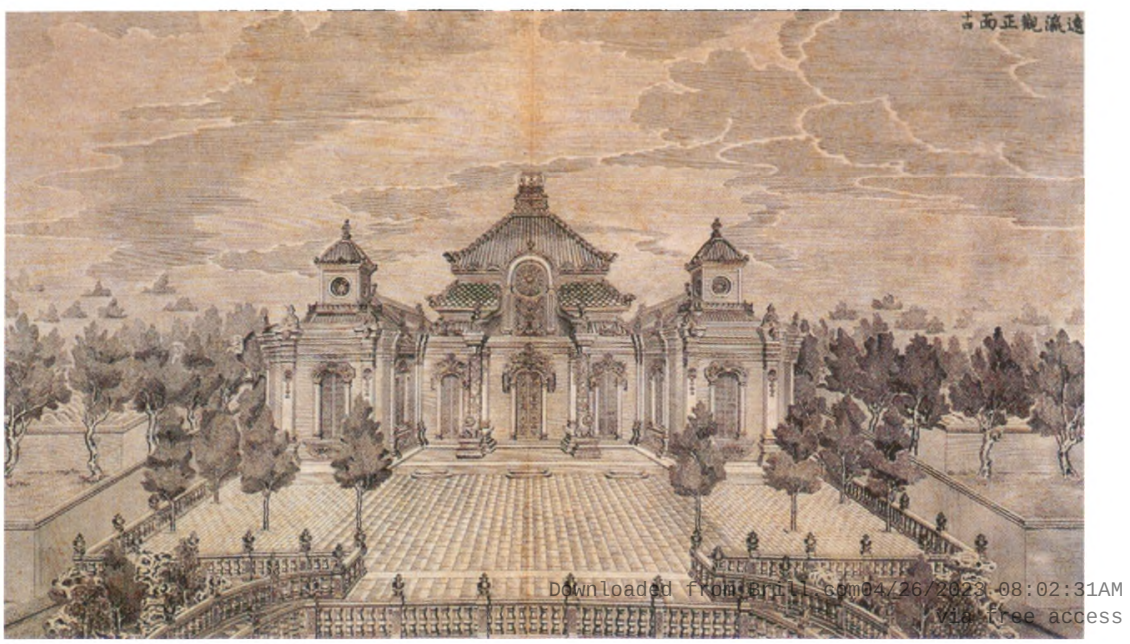




\section{Afbeelding 7}

'Han jia liang',

houtsnede, illustratie uit

Xiqing Gujian,

keizerlijke catalogus,

voltooid in 1751, juan

(boek) 34, p. 1-2

Uit: Liu Tuo e.a. (red.),

Qingdian banhua

huikan, Beijing, 1998,

Vol. 7, p. 730
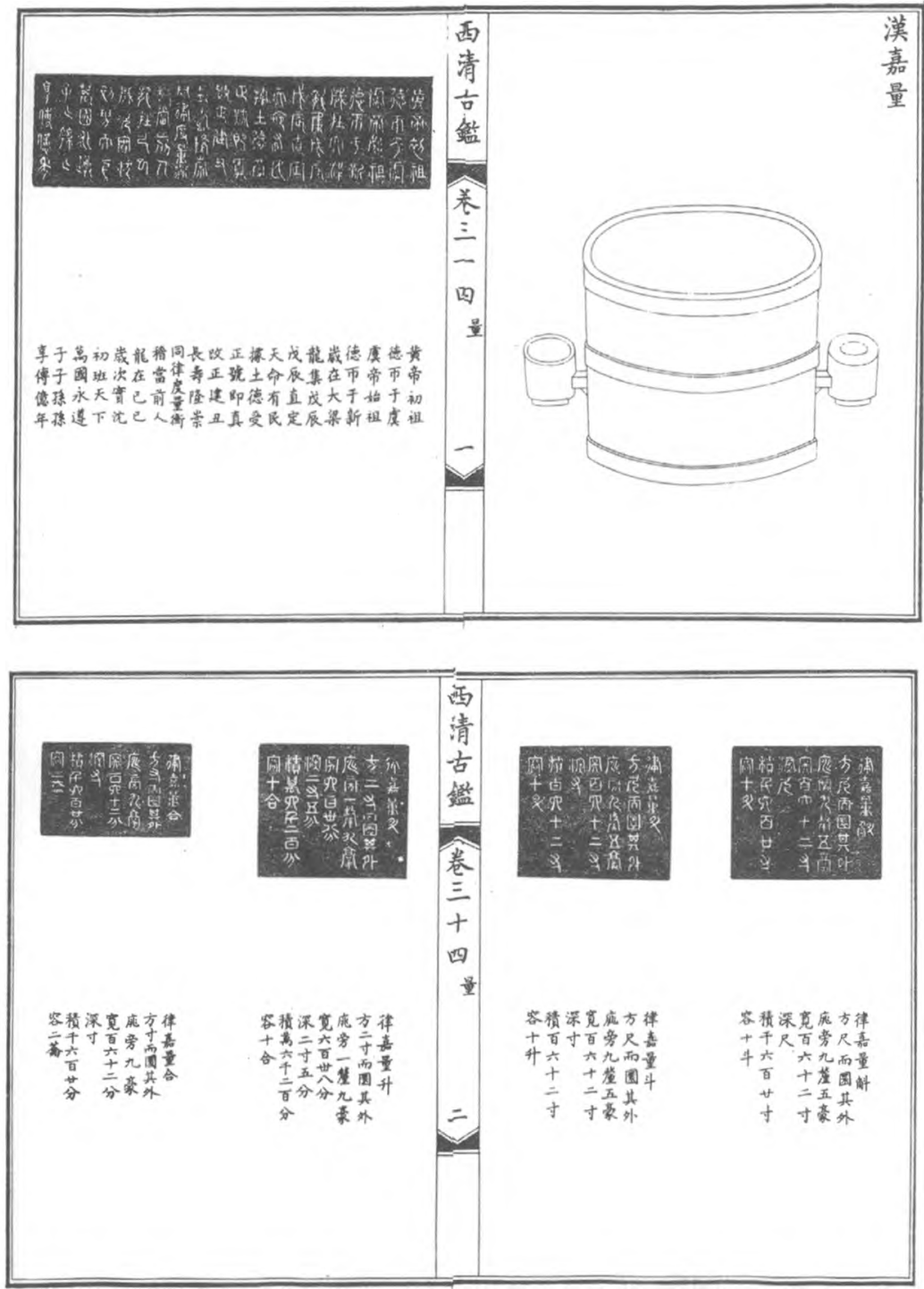

\section{Afbeelding 8}

Standaardmaat (liang), gedateerd $9^{e}$ eeuw, brons, diameter $34 \mathrm{~cm}$, hoogte $25,6 \mathrm{~cm}$ Uit: Fong en Watt (zie noot 2), pl. 51

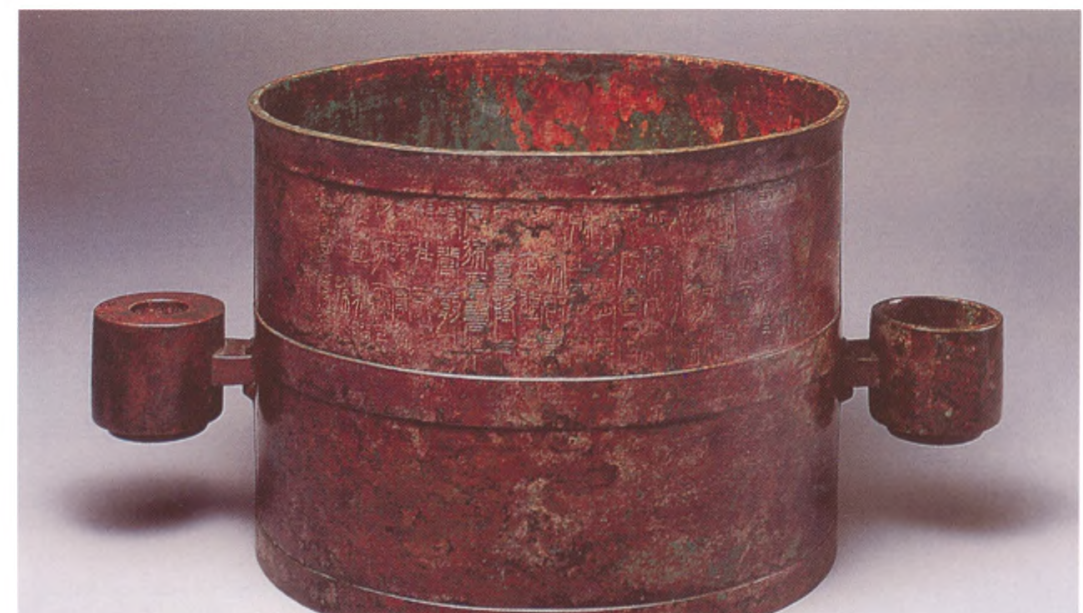


'machines' - ongetwijfeld een verwijzing naar het grote aantal Europese klokken en automata die gretig door Qianlong waren bemachtigd. ${ }^{3}$ Het Zicht op Yuanyingguan komt uit een set van 20 kopergravures die de Europese paleizen en tuinen van het Yuanmingyuan ('de tuin van perfecte pracht') afbeeldden. Deze overweldigende gebouwen, ontworpen door de jezuïtische missionariskunstenaars aan het keizerlijk hof, waren gebouwd tussen 1747 en 1759 met als slotstuk de bouw van Yuanyingguan in 1768. Deze Europese paleizen hadden geen woonfunctie en dienden voornamelijk om een gemengd Chinees-Westerse aanblik van exotisch Europa te bieden aan keizer Qianlong.

Keizer Qianlongs betrokkenheid bij de traditie van keizerlijke geleerdheid - met name het opdracht geven tot de samenstelling van catalogi van de keizerlijke collecties - is ontleend aan keizer Huizong van de Noordelijke Song-dynastie (r. 1100-1126). Qianlongs Xiqing gujian-catalogus ('collectie van antieke bronzen van het Xiqing Paleis') is een regelrechte nabootsing van Huizongs Xuanhe bogu tu ('illustraties van antiquiteiten van de Xuanheperiode'), de catalogus van antieke bronzen die door keizer Huizong waren verzameld aan het begin van de $12^{\mathrm{e}}$ eeuw. Een toelichting van in totaal vier pagina's uit Qianlongs catalogus (afb. 7) geeft enig idee van de omvang. De nadruk in de keizerlijke catalogus ligt op de inscripties op de oude bronzen. De catalogus bevat een weergave van rubbings van de inscripties samen met transcripties. Daarna volgt nog een viertal pagina's met afmetingen en commentaar. De door de keizerlijke catalogiseringscommissies toegepaste technieken vertonen verrassende overeenkomsten met die uit onze tijd, met hun nadruk op de zorgvuldige weergave van afmetingen en andere details. Oude bronzen met inscripties vormden het voornaamste bewijs van de juistheid van de geschiedenis en dienden derhalve om opgetekende geschiedverhalen te bevestigen, om fouten recht te zetten en zelfs om vervalsingen aan het licht te brengen. De geschiedenis werd zo ten dele vastgelegd door de keizerlijke opdracht tot het samenstellen en publiceren van catalogi van de oude bronzen. Andere objecten uit de collecties van Qianlong werden opgetekend in een zelfde soort catalogi. Deze dienen op hun beurt als visuele inventarissen van de keizerlijke collecties, omdat ze verwijzen naar de talloze objecten die niet te bezichtigen waren in de vele hallen en paleizen van de Verboden Stad.

Het bezit van kunstschatten was bepalend voor de wettiging van een dynastie. Bezit van de keizerlijke collectie verleende morele en politieke autoriteit en dient zelfs nog heden ten dage gelijksoortige doelen. ${ }^{4}$ Het brons dat staat afgebeeld in Qianlongs Xiqing gujian-catalogus (afb. 8), tegenwoordig in het Paleismuseum in Taipei, is zelf onderdeel van de vestiging van een dynastie. Hoewel het in de keizerlijke catalogus wordt aangeduid als een Han-brons, was het eigenlijk gegoten in de Wang Mang-periode, de zogeheten Xindynastie tussen de Westelijke en de Oostelijke Han-dynastieën. Het brons is gedateerd overeenkomend met het jaar 9, en elk deel van het vat is een zorgvuldig berekende inhoudsmaat. Daarmee belichaamt het de officiële rol van de eerste keizer van een dynastie door standaardmaten voor de opvolgers vast te stellen. ${ }^{5}$ Naast standaarden voor inhoud, afstand en gewicht was er ook een standaard voor muzieknoten. Muziek van was groot belang in het keizerlijk ritueel.

Foto's van Chinese kunst in moderne publicaties neigen ertoe om op vee $b: 02: 31 \mathrm{Am}$ manieren de idealen van hedendaagse museumvertoon na te bootsena dee access 


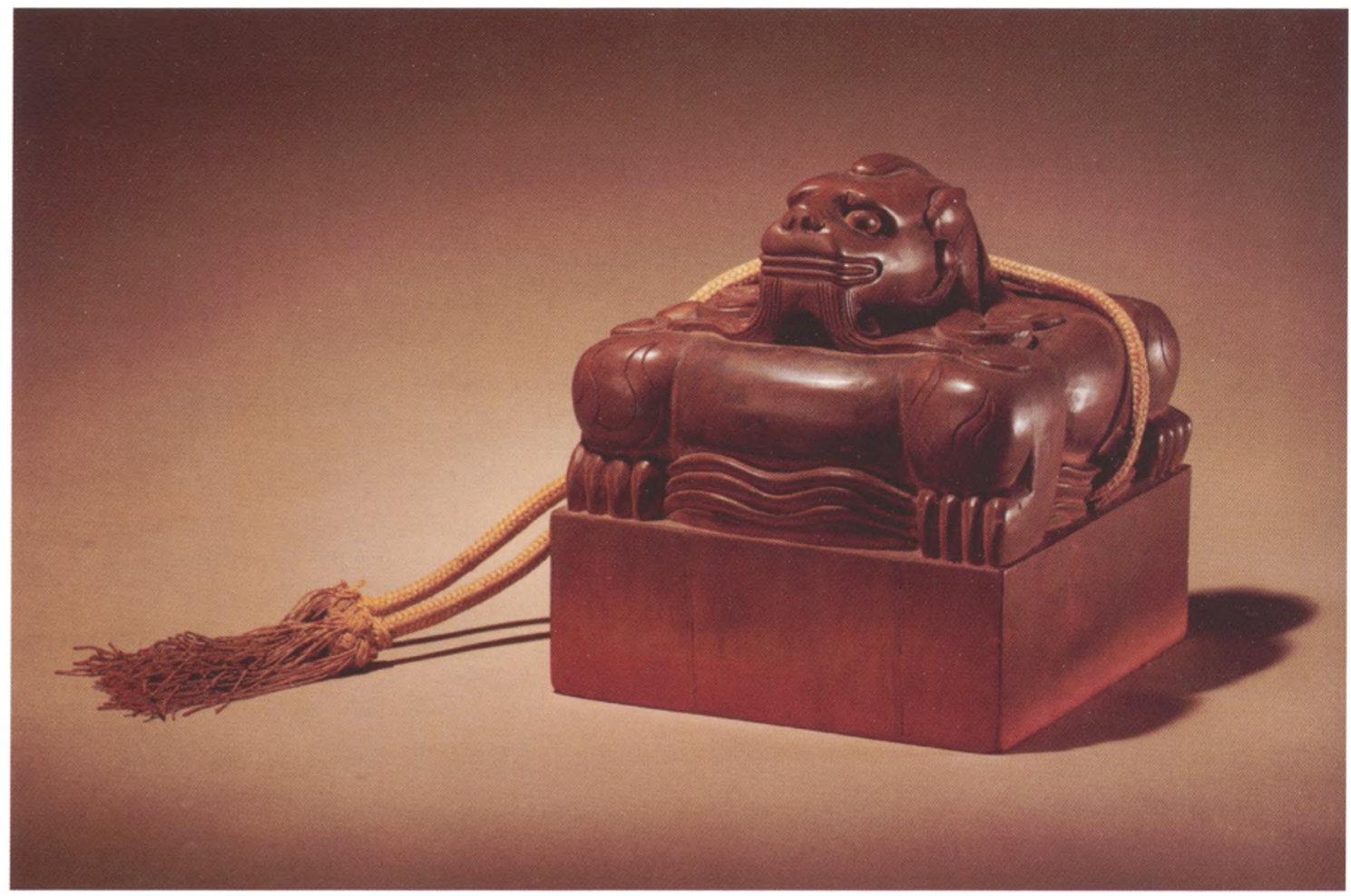

Afbeelding 9

Sandelhouten zegel met de tekst 'Schat van de Keizer' in het Chinees en het Manchu, 1748, $15,4 \times 15,4 \mathrm{~cm}$ Uit: Wan Yi e.a. (red.), Qingdai gongting shenghuo, Hongkong, 1985 , cat. 7 objecten zijn helder belicht en de kunstwerken worden vaak getoond als esthetische objecten ter contemplatie door de lezer. Een goed voorbeeld hiervan is een foto van een van Qianlongs vele zegels (afb. 9). De bewerkte palmhouten zegel behoort tot de groep van 25 belangrijkste zegels van Qianlong. Het opschrift dat in spiegelschrift gekerfd staat aan de onderzijde van de zegel om op keizerlijke edicten te stempelen is hier niet zichtbaar - de woorden 'Schat van de Keizer', zowel in het Chinees als in het Mantsjoe. Doorgaans werden Qianlongs 25 grote zegels bewaard in dozen in de Jiaotai Dian, de 'Hal van Verbintenis' (afb. 10). ${ }^{\circ}$ Elk zegel zat in een afzonderlijke, gesloten doos van hout en metaal (twee van deze roodgekleurde dozen zijn - onbedekt - rechts en links op de foto van afbeelding 10 te zien). Elke doos staat op een viervoetige steun, die op zijn beurt weer op een basis staat en elk is normaliter afgedekt door een keizerlijk gele zijden hoes. De volledige groep van 25 stempels staat symmetrisch opgesteld rond de troon midden achterin de hal. Achter de troon bevindt zich Qianlongs eigen tekst: 'de Optekening van de Jiaotai Dian'. De buitengewone wijze van opbergen van deze zegels benadrukt hun alles overheersende belang voor de keizer. De bewerkte steunen tonen ons de rituele waarde van de zegels, en niet zozeer hun status van 'kunstwerk', en hun plaats ten opzichte van de troon bekrachtigt nog eens hun gewichtige betekenis. Deze zegels die tegenwoordig staan afgebeeld in kunstboeken of van alle kanten zijn te bezichtigen in museumvitrines, waren zo goed als onzichtbaar aan het $18^{\mathrm{c}}$-eeuwse Qing-hof.

Het tentoonstellen van kunstschatten gebeurde vaak met een van de vele, over de diverse paleishallen verspreide keizerlijke tronen van de Qing als middelpunt. Een illustratie uit een recent boek over de Verboden Stad 
toont de plattegrond van de Yangxin Dian, de 'Hal voor het Koesteren van de Ziel', die ook Qianlongs voornaamste verblijfplaats in het keizerlijk paleis was. Verplaatsbare componenten zoals meubels en objecten zijn blauw afgebeeld en de vaste architectuur is hier zwart. Hier zien we herhaalde malen de standaardopstelling met een troon, geplaatst op de centrale as voor een scherm, gericht naar de hoofdingang, en een min of meer strikte symmetrische verdeling van het meubilair en de objecten rondom de troon. De integratie van kunstwerken met de troonopstelling is verschillend, afhankelijk van de hiërarchische betekenis van een ruimte - van de meer formele naar de minder formele, maar daarom niet minder belangrijke 'privé-ruimtes', verder naar de zijkanten van het gebouw. De opstelling is doorgetrokken tot in de

Afbeelding 10 Interieur van de Jiaotai Dian Uit: Wan Yi, Op.cit. (zie afb. 9), fig. 12

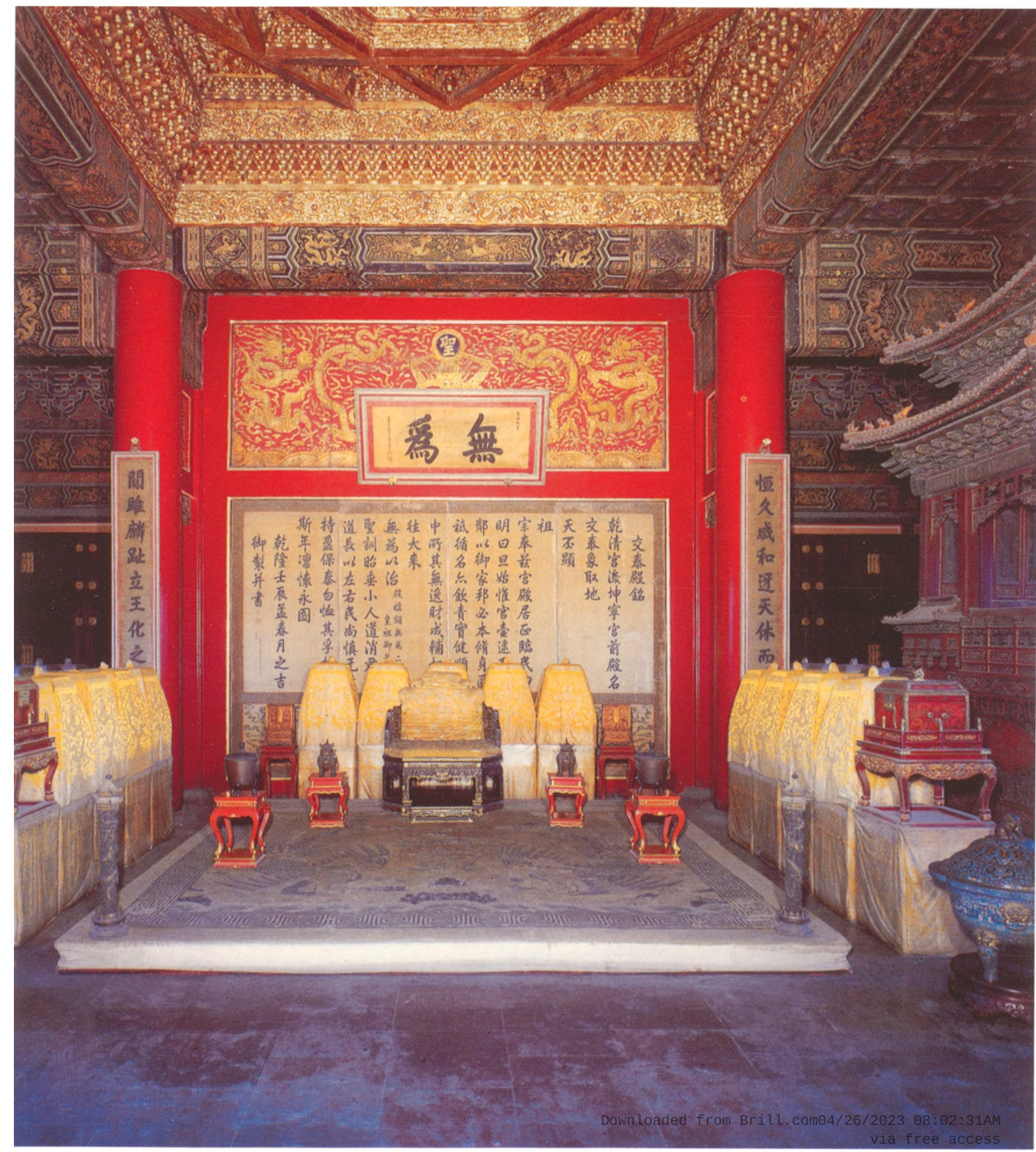




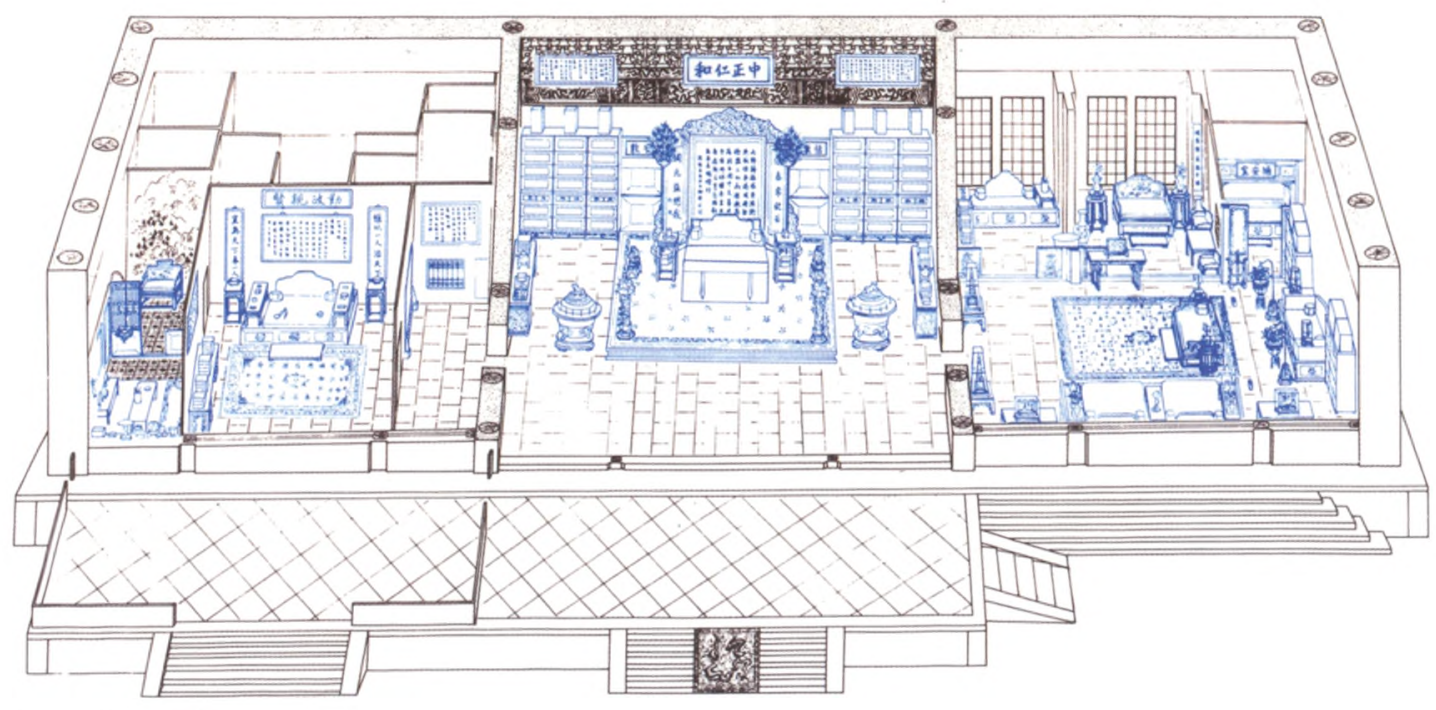

Afbeelding 11

Binnenkamers van Yangxin Dian Uit: Yu Zhuoyun (red.), Palaces of the Forbidden City,

Harmondsworth/New York, 1987, fig. 30, p. 90 kleinste, meest intieme delen van de keizerlijke vertrekken: de kamers die tezamen de Sanxi Tang vormen, de 'Hal van de Drie Zeldzaamheden', aan de linkerkant van de illustratie. Het moge duidelijk zijn dat de indeling, zo consequent doorgevoerd, op vele manieren gericht is op het eerbetoon aan de persoon van de keizer, die zetelde op de centraal opgestelde troon. De 'Hal van de Drie Zeldzaamheden' ontleende zijn naam aan drie belangrijke kalligrafieën die daar officieel werden bewaard. De naam staat op veel keizerlijke zegels van Qianlong, hetgeen er ofwel op duidt dat schilderingen of kalligrafieën officieel werden geboekstaafd als onderdeel van deze kamers ofwel dat de keizer ze daar had gezien en gewaardeerd.

Op het eerste gezicht lijkt het merkwaardig dat er maar zo weinig hofschilderingen bestaan die het tonen of het bezichtigen van schilderingen afbeelden, terwijl er toch een grote hoeveelheid schilderijen en kalligrafieën in de keizerlijke collectie aanwezig is, zowel van oude als eigentijdse meesters. Het belang van schilderkunst en kalligrafie voor keizer Qianlong wordt nog eens extra bevestigd door het indrukwekkende aantal inscripties en door de vele teksten die de keizer speciaal schreef voor of over kunstwerken. In de geschiedenis van de Chinese schilderkunst bestaan er veel afbeeldingen van geleerden die schilderijen bestuderen, vaak in gezelschap van een klein groepje collega's, soms in een tuin. Meestal staan ernaast nog andere kunstwerken - antiquiteiten, porseleinen en dergelijke - ter bezichtiging opgesteld. Maar afbeeldingen van keizer Qianlong lijken veelal politiek te zijn geladen en laten maar zelden een moment van eenvoudige beschaafde ontspanning zien.

Een schilderij dat dat wel doet, toont keizer Qianlong die in een tuin een rolschildering bestudeert (afb. 12). De keizer zit op een stenen bankje met een bediende achter zich die een waaie ban pauwenveren vasthoudt een $_{\text {: }}$ 2: 31AM keizerlijk embleem. Op tafel liggen verschillende soorten kunstobjectenfree access 
Afbeelding 12 Giuseppe Castiglione (1688-1766), Keizer Qianlong bestudeert Schilderijen, hangrol, inkt en kleur op papier, $1746-50,135,4 \times 62 \mathrm{~cm}$ Uit: Rawski en Rawson (zie noot 7), cat. 194

\section{Afbeelding 13} Anoniem, Portret van Ni Zan, handrol, inkt en kleur op papier, rond 1340, 28, 2 × 60,9 cm. Uit: Fong en Watt (zie noot), pl. 155

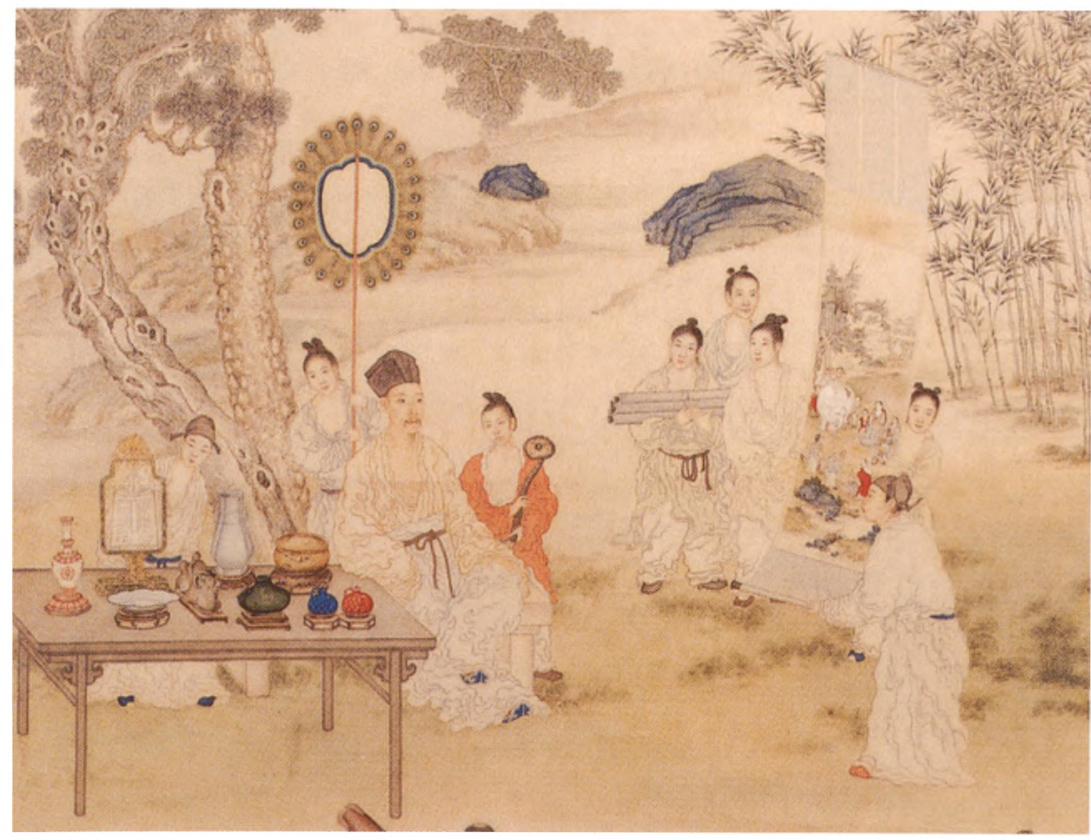

waarvan een aantal kan worden geïdentificeerd als specifieke objecten uit de keizerlijke collecties. Een andere bediende heeft zijn armen vol met opgerolde schilderijen, terwijl een derde bediende en een man (waarschijnlijk een ambtenaar) een schildering omhooghouden zodat de keizer die kan bekijken. Het is moeilijk te zien, maar deze uitgerolde schildering die door Qianlong wordt bestudeerd is een schilderij van de bodhisattva Manjusri die kijkt naar monniken die een witte olifant poetsen. De afbeelding vormt een rebus, een woordenspel, die verwijst naar de boeddhistische doctrine van het wegpoetsen van illusies van waarneembare verschijnselen. Kort tevoren had keizer Qianlong opdracht gegeven voor dit specifieke portret, nadat hij een beroemde Ming-schildering had verworven waarop het wassen van een witte olifant was afgebeeld. De keizer had toen trouwens meteen een versie van

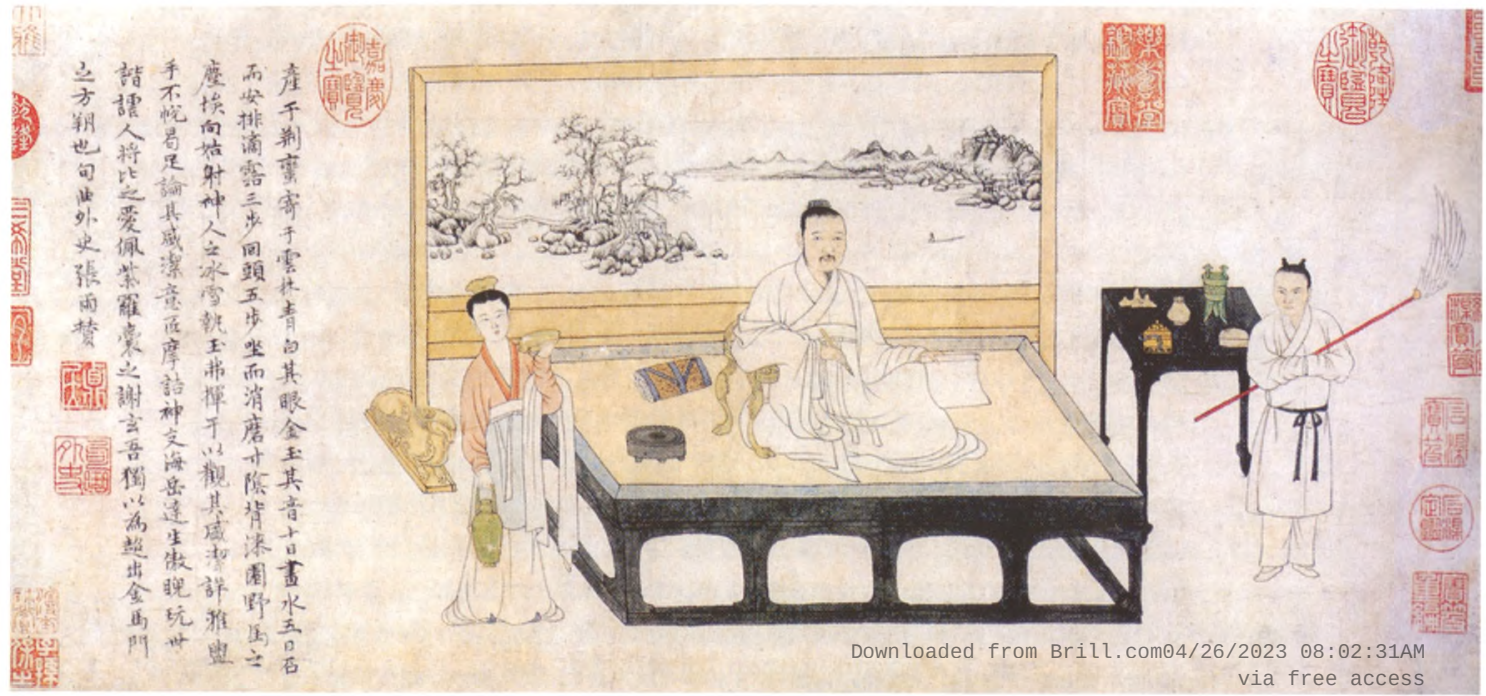



Maar hier kijkt hij klaarblijkelijk naar het originele Ming-schilderij. ${ }^{7}$

Qianlongs stempels op de schilderijen vertellen ons dat de schilderijen tot de keizerlijke collecties behoorden en, soms, over de gelegenheden waarbij deze werden opgesteld ter keizerlijke bezichtiging. Die stempels tonen aan dat keizer Qianlong het anonieme $14^{\mathrm{C}}$-eeuwse portret van schilder en kalligraaf Ni Zan (1301-1374) vele malen bekeek (afb. 13). Ni Zan werd altijd geëerd als een van de belangrijkste personen in de geschiedenis van de Chinese kunst, en zijn portret was dan ook zorgvuldig gecatalogiseerd in de keizerlijke Qing-collecties. ${ }^{8}$ Het bezit van dit portret - en veel van Ni Zans originele schilderijen - illustreerde dat de keizer zich ervan bewust was dat hij de tradities van verzamelen en kennerschap volgde. Op het portret van deze cruciale figuur in de Chinese kunstgeschiedenis is een geleerde-kunstenaar afgebeeld die op het punt staat om iets te scheppen: Ni Zan zit ontspannen op een grote verhoging met inkt en een penseel in de aanslag, wit papier in de hand om op te schilderen of te schrijven, en antiquiteiten in de buurt ter inspiratie. Het landschap op het scherm achter de kunstenaar is een imitatie van zijn schilderstijl en een typische 'Ni Zan-compositie'.

Van één opvallende afbeelding van keizer Qianlong bestaan verschillende versies (afb. 14). Het originele ontwerp diende als een scherm gemonteerd te worden en hier is de oudste versie van het schilderij op een tafelscherm geprojecteerd zodat we ons een voorstelling kunnen maken van hoe het er in eerste instantie uitzag en welk nut het had. Dit schermportret van keizer Qianlong is deels gebaseerd op een vroege albumschildering in de keizerlijke collectie: een afbeelding van een geleerde die op een bank voor een scherm zit en antiquiteiten bestudeert. Dat kleine schilderij, waarvan de keizer meende dat het een meesterwerk uit de Song-dynastie betrof, toont een merkwaardig schouwspel: een portret van de zittende man hangt over het scherm en het is alsof dat portret binnen het schilderij neerziet op zijn eigen onderwerp. Portretten van zittende geleerden-connaisseurs zijn over het algemeen niet ongebruikelijk, en hier had de keizer opdracht gegeven tot het maken van een afbeelding in diezelfde traditie - een afbeelding waarin hij op vele manieren de rol van Ni Zan als kenner, kalligraaf, en schilder naspeelt. Hij heeft een penseel en een witte papierrol in zijn handen, zich voorbereidend op, wellicht, het maken van een gedicht, een kalligrafie of een schilderij - bekwaamheden van een geleerde, alle door Qianlong beoefend. Het scherm op de achtergrond toont een hoge waterval in een berglandschap, weergegeven in de kenmerkende stijl van Ni Zan. In dit schermportret van de keizer zijn enkele kunstobjecten uit de keizerlijke Qing-collectie te herkennen, waaronder de porseleinen pot uit de Xuande-periode die was afgebeeld in de rolschildering met antiquiteiten van keizer Yongzheng (rechts achterin op het scherm, zie afbeelding 3) en het brons uit de Wang Mang-periode (helemaal links op het scherm, zie afbeelding 8). De objecten uit de keizerlijke collecties lijken uit te waaieren met de keizer als stralend middelpunt. Het belang van het bezit van deze gewaardeerde kunstschatten wordt daarmee tot uitdrukking gebracht evenals de plaats van de keizer in de tradities van verzamelen en kennerschap. Deze kunstschatten zijn opgesteld rondom zijn troon op meubelstukken in Chinese en Europese stijl, maar minder formeel dan de traditionele indeling van een keizerlijke troon voor een scherm, waaruit,men kan afleiden datb dit eennintieme 31AM $_{31}$ scène is, misschien keizer Qianlong alleen, slechts vergezeld door zijn bejediendecess 


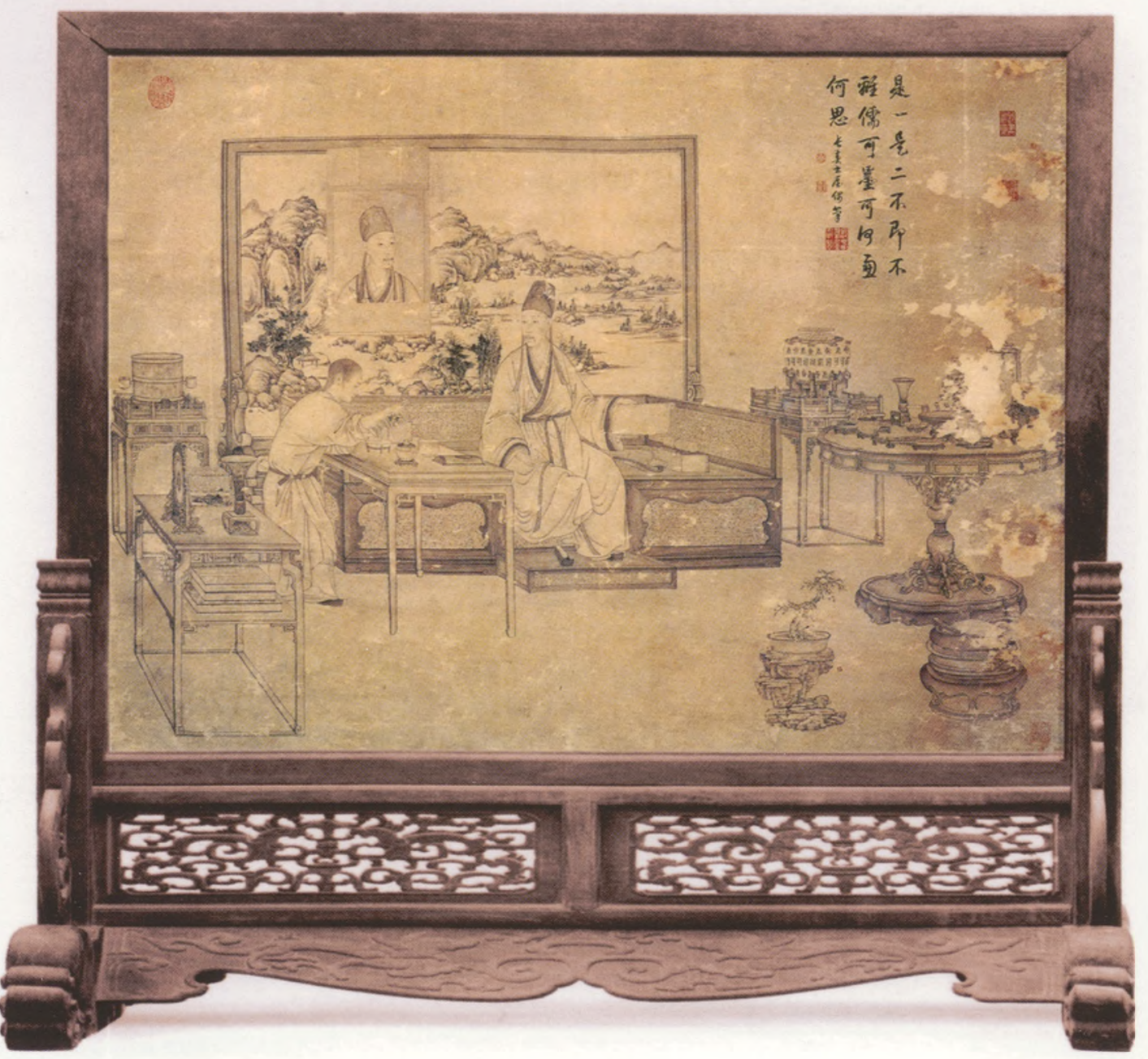

Afbeelding 14 Yao Wenhan (18 eeuw), Eén of Twee?, hangrol, inkt op papier, ca. 1745 uit: Qingdai gongting huihua (zie afb. 1), cat. 81
Het schilderij is opgezet volgens een schema met lijnperspectief en één verdwijnpunt, een tekentechniek uit de Europese kunst die was overgedragen door de jezuïtische missionariskunstenaars zoals Giuseppe Castiglione (1688-1766, jaar van aankomst in China 1715), die actief waren aan de Keizerlijke Schilder Academie van de Qing. Het naturalistische portret van de keizer, dat sterke gelijkenis vertoont met portretten van Castiglione, is driekwart gedraaid, en de lichte schaduw op zowel personen als meubilair is toegepast volgens Europese schildertechnieken. De ogen van het 'tweede' portret van de keizer - het kleine portret binnen de grotere afbeelding - staan op dezelfde hoogte als de ogen van een staande toeschouwer, en vormen tevens de horizon van het lijnperspectief. Het scherm moest een illusionair beeld scheppen waarin keizer Qianlong voor het scherm gezeten was waarop hij ook was afgebeeld, zittend voor een scherm waarop het portret van de keizer duidelijk zichtbaar was. 
Aanwijzingen voor de bedoeling die de keizer had met het verstrekken van de opdracht voor dit opvallende schilderij zijn gelegen in de inscriptie die begint met de vraag: 'Is het er één of zijn het er twee?' Net als het portret waar de keizer het schilderij van bodhisattva Manjusri bestudeert, is ook deze afbeelding gemaakt in het midden van de $18^{\mathrm{C}}$ eeuw, een tijd waarin keizer Qianlong zich diepgaand bezighield met de studie van de Tibetaanse school van Madhyamika boeddhisme. Qianlongs twijfel aan de aard van de werkelijkheid in de formule 'één of twee' verwijst specifiek naar de leer van non-dualiteit, de wederzijdse afhankelijkheid van alle verschijnselen en de onwezenlijkheid van fysieke verschijningsvormen. ${ }^{9}$ Doordat keizer Qianlong gebruik maakte van de meest 'realistische' stijl die hij voorhanden had Europees lijnperspectief, zorgvuldige weergave en individuele portretschildering op grond van scherpe observatie - en zich omringde met beroemde producten van traditioneel verzamelen en kennerschap, lijkt hij aan te geven dat hij zelf de ware essentie van de kunstschatten en van zijn eigen persoon kent, en dat ze hier voor een ieder ter overweging zijn tentoongesteld. Met deze daad van zelfonderzoek en zelfkennis, voegde keizer Qianlong een radicaal nieuwe dimensie toe aan de Chinese traditie van verzamelen en kennerschap.

Wanneer we nu kijken naar Chinese kunstschatten - bronzen, jades, porseleinen, schilderijen en kalligrafie - in een museumopstelling, zien we interpretaties van de objecten die keizer Qianlong bekend zouden zijn voorgekomen. Maar het komt minstens zo vaak voor dat die interpretaties sterk verschillen van wat de keizer zelf in de $18^{\circ}$ eeuw ervaren zou hebben.

\section{Noten}

1. S. McCausland, 'The Emperor's Old Toys: Rethinking the Yongzheng (1723-35) Scroll of Antiquities in The Percival David Foundation', Transactions of the Oriental Ceramic Society 66 (2001-2002), pp. 65-75.

2. W.C. Fong, J.C.Y. Watt e.a., Possessing the Past: Treasures from the National Palace Museum, Taipei (tent.cat. National Palace Museum, Taipei en Metropolitan Museum of Art, New York), 1996, Hoofdstuk 23, 'The Antique-Elegant', en 'Packaging the Collections', pp. 547-549.

3. L.-Fr. Delatour, Essais sur l'architecture des Chinois, sur leurs jardins, leurs principes de médecine, et leurs moeurs et usages..., Parijs, 1803, p. 165.

4. Zie van de vele studies naar de rol van de keizerlijke collecties: R.E. Scott, 'The Chinese Imperial Collections', in: S. Pierson (red.), Collecting Chinese Art: Interpretation and Display (Colloquies on Art \& Archacology in Asia No. 20), Londen, 2000, pp. 19-32; Chang Lin-Sheng, 'The National Palace Museum: A History of the Collection', in: Fong en Watt, Op.cit. (noot 2). pp. 3-25; J. Shambaugh Elliott en D.Shambaugh, The Odyssey of China's Imperial Art Treasures, Seattle/London, 2005.

5. Voor de discussie over de complexe metingen en politieke implicaties weergegeven door deze vaas, zie Fong en Watt, Op.cit. (noot 2), pp. 93-95 en 577-578.

6. Chuimei Ho en B. Bronson, Splendors of China's Forbidden City: The Glorious Reign of Emperor Qianlong, London, 2004, pp. 58-59.

7. Voor een discussie over de huidige schildering, Qianlong's portret als Manjusri, en het Ming-model, zie Gerald Holzwarth's catalogus lemmata nummers 194 en 195 in: E.S. Rawski en I. Rawson, China: The Three Emperors, 1662-1795 (tent.cat. Royal Academy of Arts), Londen, 2005. pp. 438-4390. De boeddhistische himplicaties van het $31 \mathrm{AM}$ onderwerp zijn deels gebaseerd op de homofonen van het karakter xiang voor ree access 
'olifant' en een ander karakter xiang voor 'afbeelding'. Zie ook P. Berger, Empire of Emptiness, Buddhist Art and Political Authority in Qing China, Honolulu, 2003), p. 63. Bergers onderzoek naar de boeddhistische implicaties van kunst tijdens de Qianlong-regering geeft veel informatie over de discussie hier.

8. M. Hearn, 'The Artist as Hero' en 'The Portrait of Ni Tsan', in: Fong en Watt, Op.cit. (noot 2), pp. 312-314.

9. Dit schilderij is veelvuldig besproken en de betekenis ervan is veelvuldig bediscussieerd. In aanvulling op Holzwarth, Op.cit. (noot 7), zie ook P. Berger, Op.cit. (noot 7), pp. 51-54; A. Zito, Of Body and Brush: Grand Sacrifice as Text/Performance in Eighteenth-Century China, Chicago, 1997, met name pp. 38-43; Wu Hung, The Double Screen: Medium and Representation in Chinese Painting, Chicago, 1996, pp. 231-236; Zhang Hongxing, The Qianlong Emperor: Treasures from the Forbidden City (tent.cat. National Museum of Scotland), Edinburgh, 2002, cat. 59. pp. 112-113. Bergers analyse van de boeddhistische context lijkt het meest subtiel en overtuigend. 